\title{
THE PREPARATION OF OXYGENATED DERIVATIVES OF AMBROX AND ISOAMBROX FROM DRIMENOL
}

\author{
JULIO BENITES ${ }^{\prime *}$, JOSE LOPEZ ${ }^{1}$, JORGE G. FARIAS ${ }^{l}$ AND MANUEL CORTES
}

${ }^{1}$ Departamento de Química, Universidad Arturo Prat, Iquique, Chile.

${ }^{2}$ Facultad de Química, Pontificia Universidad Católica de Chile, Santiago, Chile.

\begin{abstract}
The preparation of oxygenated derivatives of ambrox and isoambrox is described. The compounds $7 \alpha$-hydroxy-isoambrox, $7 \beta$-hydroxy-isoambrox, $7 \alpha$ hydroxy-ambrox, 7 $\beta$-hydroxy-ambrox, 7-oxo-isoambrox and 7-oxo-ambrox have been synthesized from (-)-drimenol, readily available from the bark of Drimys winteri. The structures of the products were determined mainly by spectroscopic methods.
\end{abstract}

Key words: Ambrox, Isoambrox, Ambergris

\section{INTRODUCTION}

Ambergris is one of the most valuable animal perfumes, like civet, musk and castoreum. ${ }^{1,2}$ This substance is a metabolic product of the blue whale (Physeter macrocephalus) sperm that accumulates in the gut of the animal. It has been used for centuries because of its unique fragrance and fixative properties, ${ }^{3}$ but is now commercially banned or taken off the market thanks to the Marine Mammals Protection Act. Extensive reviews with detailed studies correlating their structure with smell, synthetic efforts, etc., are available. ${ }^{4}$

The most important equivalent of this scarce natural source is the norlabdane oxide Ambrox ${ }^{\circledR}$ (1) (trade name of Firmenich SA). The growing demand for ambergris-type odorants has stimulated an intense search for substitutes. For this reason various synthetic routes to Ambrox and Isoambrox have been developed. ${ }^{5-10}$
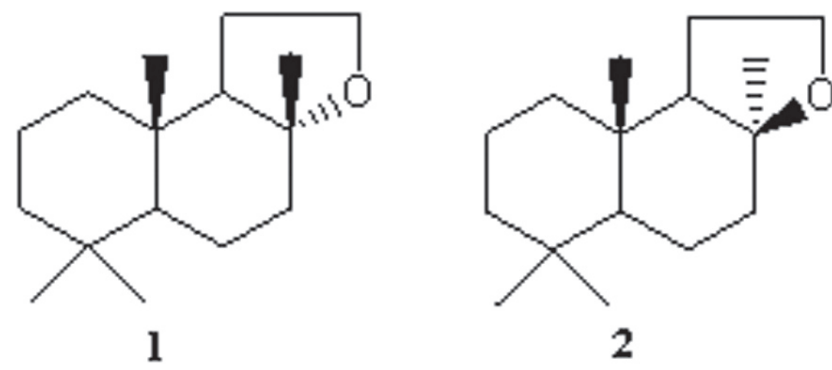

Figure 1. Structures of Ambrox (1) and Isoambrox (2)

Using the framework of our studies of natural sesquiterpenes to provide materials for the preparation of various ambergris type compounds, ${ }^{11-13}$ we are now describing the formal synthesis of the oxygenated derivatives of Ambrox and Isoambrox $3,4,5,6,7$ and 8 . The starting material was the sesquiterpene (-)-drimenol, readily available from the bark of Drimys winteri. ${ }^{14}$<smiles>CC1(C)CCC[C@@]2(C)C1C[C@H](O)[C@]1(C)OCC[C@@H]21</smiles><smiles>CC1(C)CCC[C@]2(C)C1C[C@@H](O)[C@@]1(C)OCCC12</smiles>

6<smiles>CC1(C)CCCC2(C)C1CC(=O)[C@]1(C)OCCC21</smiles>

4<smiles>CC1(C)CCC[C@@]2(C)C1CC(=O)[C@]1(C)OCC[C@H]21</smiles>

7<smiles>CC1(C)CCC[C@@]2(C)C1C[C@H](O)[C@]1(C)OCC[C@@H]21</smiles>

5

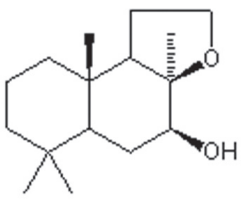

8 3 - 8

Figure 2. Structures of oxygenated derivatives of Ambrox and Isoambrox

\section{EXPERIMENTAL}

Melting points were measured on a Kofler hot stage apparatus and are uncorrected. Optical rotations were obtained for chloroform solutions on a Perkin-Elmer 241 polarimeter, and their concentrations are expressed in $\mathrm{g} / 100$ $\mathrm{mL} .{ }^{1} \mathrm{H}$ NMR and ${ }^{13} \mathrm{C}$ NMR spectra were recorded on a Varian XL and a Bruker AW-80 spectrometers. Chemical shifts are expressed in ppm downfield relative to TMS ( $\delta$ scale) in $\mathrm{CDCl}_{3}$ solutions, and coupling constants $(J)$ are reported in Hz. Carbon multiplicity was established by a DEPT pulse sequence. IR spectra were recorded as $\mathrm{KBr}$ disks on a Bruker FT-IR 1FS 25 spectrometer and frequencies are in $\mathrm{cm}^{-1}$. Mass spectrometry measurements were made on a Finnigan 3300 and a Hewlett Packard 5930A spectrometers at an ionizing voltage of $70 \mathrm{eV}$.

For analytical TLC, Merck silica gel 60 in $0.26 \mathrm{~mm}$ layer was used. Chromatographic separations were carried out by conventional column on Merck silica gel 60 (230-400 Mesh) using hexane-EtOAc gradients of increasing polarity.

All reactions were routinely run under an $\mathrm{N}_{2}$ atmosphere. All organic extracts were dried over anhydrous magnesium sulfate and evaporated under reduced pressure at a temperature below $65^{\circ} \mathrm{C}$.

(-)-Drimenol was obtained from a light petroleum extract of the bark of Drimys winteri. ${ }^{5}$

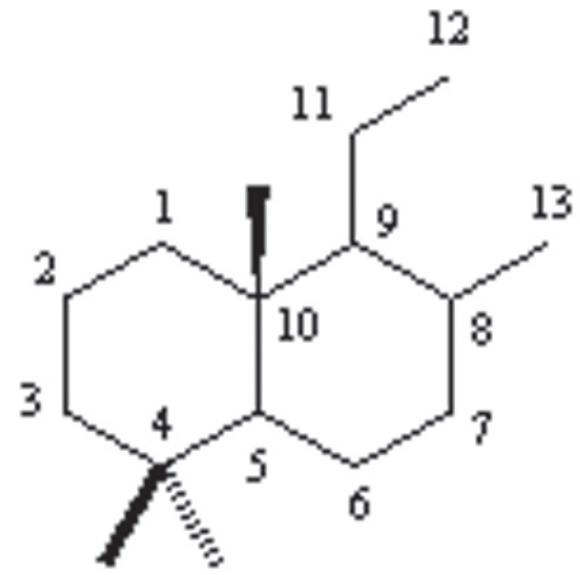

Figure 3. Compound numbering

\section{8ß-Methyl-7a,8a-epoxy-12-acetoxydrimane (10)}

To a solution of 8-methyl-12-acetoxy-7,8-drimene $(\mathbf{9})(370 \mathrm{mg}, 1.33 \mathrm{mmol})$ in $\mathrm{CH}_{2} \mathrm{Cl}_{2}, \mathrm{mCPBA}(647 \mathrm{mg}, 5.4 \mathrm{mmol}$ ) was added. The resulting solution was stirred for $1 \mathrm{~h}$ at $0{ }^{\circ} \mathrm{C}$, and it was diluted with $\mathrm{CH}_{2} \mathrm{Cl}_{2}(20 \mathrm{~mL})$, washed with saturated $\mathrm{NaHCO}_{3}(3 \times 25 \mathrm{~mL})$, water $(50 \mathrm{~mL})$, dried, and evaporated. The crude was column chromatographed on silica gel (hexane-EtOAc). Evaporation of the more polar fraction yielded $8 \beta$-methyl- $7 \alpha, 8 \alpha$-epoxy-12-acetoxydrimane (10) $\left(270 \mathrm{mg}, 69 \%\right.$ ) as a white solid: m.p $48-49^{\circ} \mathrm{C}$ (Hexane); $[\alpha]^{20}=+24.6^{\circ}$ $\left(\mathrm{c}=2.59 ; \mathrm{CHCl}_{3}\right)$. IR $v_{\text {max }} \mathrm{cm}^{-1} 2950-2860(\mathrm{C}-\mathrm{H}), 1732(\mathrm{C}=\mathrm{O}), 1360(\mathrm{C}-\mathrm{H})$, 1240 (C-O). ${ }^{1} \mathrm{H}-\mathrm{NMR}(200 \mathrm{MHz}): \delta 4.11$ (m, 2H, H-12); 2.96 (m, $\mathrm{W}_{1 / 2} 7 \mathrm{~Hz}$, 
1H, H-7), 2.04 (s, 3H, AcO), 1.32 (s, 3H, 10-Me); 0.85 (s, 6H, 4-Me- $\alpha+8-\mathrm{Me}-$ $\beta) ; 0.74$ (s, 3H, 4-Me- $\beta$ ). ${ }^{13} \mathrm{C}-\mathrm{RMN}$ (50 MHz): $\delta 170.5$ (AcO), 65.0 (C-12); 60.5 (C-7); 57.9 (C-8); 51.2 (C-5); 45.3 (C-9); 41.7 (C-3); 38.4 (C-1); 35.4 (C-10); 32.6 (C-4); 32.4 (4-Me- $\beta$ ); 24.9 (C-11); 22.7 (10-Me); 22.6 (C-6); 21.6 (4-Me- $\alpha) ; 20.6$ (AcO); 18.3 (C-2); 13.8 (8-Me- $\beta$ ).

The less polar fraction yielded $8 \alpha$-Methyl-7 $\beta, 8 \beta$-epoxy-12-acetoxydrimane $(121.3 \mathrm{mg}, 31 \%)$ as a white oil. $[\alpha]_{D}^{20}=-11.3^{\circ}\left(\mathrm{c}=2.11 ; \mathrm{CHCl}_{3}\right)$. IR $v_{\max } \mathrm{cm}$ $2950-2860(\mathrm{C}-\mathrm{H}), 1732(\mathrm{C}=\mathrm{O}), 1360(\mathrm{C}-\mathrm{H}), 1240(\mathrm{C}-\mathrm{O}) .{ }^{1} \mathrm{H}-\mathrm{NMR}{ }^{\max }(200$ MHz): $\delta 4.15$ (m, 2H, H-12); 3.01 (m, W $\left.\mathrm{W}_{1 / 2} 11 \mathrm{~Hz}, 1 \mathrm{H}, \mathrm{H}-7\right), 2.05$ (s, $3 \mathrm{H}$, $\mathrm{AcO}), 1.28$ (s, $3 \mathrm{H}, 10-\mathrm{Me}$ ); 0.88 (s, $3 \mathrm{H}, 8-\mathrm{Me}-\beta)$; 0.84 (s, 6H, 4-Me- $\alpha+4-\mathrm{Me}-$ ß). ${ }^{13} \mathrm{C}-\mathrm{RMN}(50 \mathrm{MHz}): \delta 170.8$ (AcO), 65.1 (C-12); 61.6 (C-7); 59.7 (C-8); 50.1 (C-9); 49.9 (C-5); 42.1 (C-3); 40.5 (C-1); 36.6 (C-10); 33.4 (4-Me- $\alpha$ ); 32.8 (C-4); 25.8 (C-11); 22.7 (10-Me); 21.9 (C-6); 21.6 (4-Me- $\alpha$ ); 20.8 (AcO); 17.9 (C-2); $14.9(8-\mathrm{Me}-\alpha)$.

\section{7a-Hydroxy-isoambrox (6)}

To a stirred suspension of LiAlH $(57 \mathrm{mg}, 1.5 \mathrm{mmol})$ in dry THF $(20 \mathrm{~mL})$ a solution of $8 \beta$-methyl- $7 \alpha, 8 \alpha$-epoxy-12-acetoxydrimane (10) $(220 \mathrm{mg}, 0.75$ $\mathrm{mmol})$ in dry THF $(10 \mathrm{~mL})$ was added, and the reaction mixture was stirred under nitrogen at $0{ }^{\circ} \mathrm{C}$ for $2 \mathrm{~h}$. The excess reagent was descomposed by addition of EtOAc and aqueous $10 \% \mathrm{HCl}$ solution. The mixture was then extracted with EtOAc $(3 \times 25 \mathrm{~mL})$, and the organic phase was washed with saturated $\mathrm{NaHCO}_{3}$ $(25 \mathrm{~mL})$, water $(25 \mathrm{~mL})$, dried, and evaporated. The solid obtained was column chromatographed on silica gel (hexane-EtOAc). Evaporation of the less polar fraction yielded Ambrox. The intermediate polar fraction yielded $7 \alpha$-hydroxyisoambrox (6) (44 mg, $23.3 \%$ ) as a white solid: m.p. $98-99^{\circ} \mathrm{C}$ (hexane- $\mathrm{CHCl}_{3}$ ); $[\alpha]_{\mathrm{D}}^{20}=-38.3^{\circ}\left(\mathrm{c}=1.05 ; \mathrm{CHCl}_{3}\right)$. IR $v_{\max } \mathrm{cm}^{-1} 3450(\mathrm{OH}), 2980-2830(\mathrm{C}-\mathrm{H})$ $1380(\mathrm{C}-\mathrm{H}), 1020(\mathrm{C}-\mathrm{O}) .{ }^{1} \mathrm{H}-\mathrm{NMR}$ (200 MHz): $\delta 4.11-3.66$ (m, 3H, H-7 + H-12); 1.20 (s, 3H, 10-Me); $0.93,0.88,0.87$ (3s, 9H, 4-Me- $\beta, 4-\mathrm{Me}-\alpha, 8-\mathrm{Me}-\alpha) .{ }^{13} \mathrm{C}-$ RMN (50 MHz): $\delta 85.4$ (C-8); 70.4 (C-7); 65.7 (C-12); 59.7 (C-5); 48.1 (C-9); 43.3 (C-3); 42.0 (C-1); 36.9 (C-10); 33.1 (C-4); 32.6 (4-Me- $\beta$ ); 27.5 (C-6); 26.9 (C-11); 22.4 (10-Me); 21.3 (4-Me- $\alpha) ; 18.3$ (C-2); 16.9 (8-Me- $\alpha$ ).

8 $\beta$-Methyl-7a,8a,12-drimantriol (13) and $8 \alpha-m e t h y l-7 \beta, 8 \beta, 12-$ drimantriol (14)

A solution of a mixture of $N$-methylmorpholine $N$-oxide $1.40 \mathrm{~g}(11.95$ $\mathrm{mmol}), 3 \mathrm{~mL}$ of $\mathrm{H}_{2} \mathrm{O}, 15 \mathrm{~mL}$ of acetone, and $1 \mathrm{~mL}(0.10 \mathrm{mmol})$ of $\mathrm{OsO}_{4}$ dissolved to $2.5 \%$ in $t$-butyl alcohol.was added to compound $9(1.73 \mathrm{~g}, 6.22$ $\mathrm{mmol})$ in acetone $(5 \mathrm{~mL})$. The mixture was stirred for 4 days, then poured into water $(10 \mathrm{~mL})$ and extracted with EtOAc $(4 \times 30 \mathrm{~mL})$. The combined organic layers were washed with $\mathrm{Na}_{2} \mathrm{SO}_{3}(5 \%)$ and water $(50 \mathrm{~mL})$. The major fraction $(1.90 \mathrm{~g})$, dissolved in $20 \mathrm{~mL}$ of $\mathrm{EtOH}$ and $\mathrm{NaOH}(200 \mathrm{mg})$ was added. The resulting solution was stirred for $1 \mathrm{~h}$ at room temperature and extracted with EtOAc $(6 \times 25 \mathrm{~mL})$, and the organic phase was washed with saturated $\mathrm{NaHCO}$ $(25 \mathrm{~mL})$, water $(25 \mathrm{~mL})$, dried, and evaporated. The solid obtained was column chromatographed on silica gel (hexane-EtOAc). Evaporation of the less polar fraction yielded compound $\mathbf{1 3}$ as a white solid: m.p. $152-153{ }^{\circ} \mathrm{C}$, $(\mathrm{EtOH}$ - hexane); $[\alpha]_{D}^{20}=-32.5^{\circ}(\mathrm{c}=0.83 ; \mathrm{MeOH}) . \mathrm{IR} v_{\max } \mathrm{cm}^{-1} 3300(\mathrm{OH}), 2950$ - $2840(\mathrm{C}-\mathrm{H}), 1465,1425,1380(\mathrm{C}-\mathrm{H}), 1050(\mathrm{C}-\mathrm{O}) .{ }^{\max }{ }^{1} \mathrm{H}-\mathrm{NMR}(200 \mathrm{MHz}): \delta$ $3.80-3.30$ (m, 3H, H-7 + H-12); 1.18 (s, 3H, H-20); 0.89 (s, 3H, $\left.\mathrm{CH}_{3}\right) ; 0.80$ (s, $\left.6 \mathrm{H}, 2 \times \mathrm{CH}_{3}\right)$.

The more polar fraction yielded compound $\mathbf{1 4}$ as a white solid: m.p. 109 $-110^{\circ} \mathrm{C}$ (hexane - EtOH), $[\alpha]_{D}^{20}=-12.3^{\circ}(\mathrm{c}=0.75 ; \mathrm{MeOH})$. IR $v \mathrm{~cm}^{-1} 3310$ $(\mathrm{OH}), 2940-2825(\mathrm{C}-\mathrm{H}), 1450,1380,1355(\mathrm{C}-\mathrm{H}), 1040(\mathrm{C}-\mathrm{O}) .{ }^{1}{ }^{\max } \mathrm{H}-\mathrm{NMR}(200$ MHz): $\delta 3.82$ - 3.47 (m, 3H, H-7 + H-12); 1.22 (s, 3H, H-20); 0.97 (s, 3H, $\mathrm{CH}_{3}$ ); $0.88\left(\mathrm{~s}, 3 \mathrm{H}, \mathrm{CH}_{3}\right) ; 0.84\left(\mathrm{~s}, 3 \mathrm{H}, \mathrm{CH}_{3}\right)$.

\section{7ß-Hydroxy-isoambrox (8)}

To $250 \mathrm{mg}(0.93 \mathrm{mmol})$ of $8 \alpha$-methyl-7 $\beta, 8 \beta, 12$-drimantriol (14) in $10 \mathrm{~mL}$ of dry pyridine was added $106 \mathrm{mg}(0.93 \mathrm{mmol})$ of mesyl chloride. The mixture was stirred under nitrogen at $0^{\circ} \mathrm{C}$ for $16 \mathrm{~h}$, then poured into water $(20 \mathrm{~mL})$ and extracted with EtOAc $(3 \times 30 \mathrm{~mL})$. The combined organic layers were washed with $\mathrm{HCl}(5 \%)$, saturated $\mathrm{NaHCO}_{3}$, and water, dried $\left(\mathrm{Na}_{2} \mathrm{SO}_{4}\right)$ and concentrated in vacuo. The crude product was purified by column chromatography to yield $7 \beta$-hydroxy-isoambrox $8(83.7 \mathrm{mg}, 36 \%)$ as a white solid: m.p. $84{ }^{\circ} \mathrm{C}$ (hexane$\left.\mathrm{CHCl}_{3}\right) ;[\alpha]_{\mathrm{D}}^{20}=-40.9^{\circ}\left(\mathrm{c}=1.05 ; \mathrm{CHCl}_{3}\right)$. IR $v \mathrm{~cm}^{-1} 3500(\mathrm{OH}), 2980-2840$ (C-H), 1360 (C-H), 1020 (C-O). ${ }^{1} \mathrm{H}-\mathrm{NMR}(200 \mathrm{MHz}): \delta 3.76$ (m, 2H, H-12 ); $3.31\left(\mathrm{~m}, \mathrm{~W}_{1 / 2} 24 \mathrm{~Hz}, 1 \mathrm{H}, \mathrm{H}-7\right) ; 1.20(\mathrm{~s}, 3 \mathrm{H}, 10-\mathrm{Me}) 0.90,0.87$ (2 x s, 9H, 4-Me$\beta, 4-\mathrm{Me}-\alpha, 8$-Me- $\alpha$ ). ${ }^{13} \mathrm{C}-\mathrm{RMN}(50 \mathrm{MHz}): \delta 86.1$ (C-8); 76.2 (C-7); 64.5 (C12); 57.8 (C-5); 50.5 (C-9); 41.6 (C-3); 41.3 (C-1); 36.2 (C-10); 33.4 (4-Me- $\beta$ ); 32.7 (C-4); 28.1 (C-6); 26.5 (C-11); 24.0 (10-Me); 22.2 (4-Me- $\alpha$ ); 18.1 (C-2);
14.9 (8-Me- $\alpha$ ). MS $m / z$ (rel. int.): $252\left[\mathrm{M}^{+}, \mathrm{C}_{16} \mathrm{H}_{28} \mathrm{O}_{2}\right]$ (55); 237 (7); 137 (100); 124 (40); 123 (5); 109 (26); 107 (5); 96 (1); 95 (7); 84 (7); 83 (10); 82 (7); 81 (11); 44 (45); 81 (17); 41 (31).

\section{7-Oxo-isoambrox (7)}

To a stirred solution of $7 \beta$-hydroxy-isoambrox $(\mathbf{8})(40 \mathrm{mg}, 0.16 \mathrm{mmol})$ in $10 \mathrm{~mL}$ of $\mathrm{CH}_{2} \mathrm{Cl}_{2}, \mathrm{PCC}$ reagent $150 \mathrm{mg}(0.70 \mathrm{mmol})$ was added dropwise at room temperature. The reaction was monitored by TLC until disappearance of the starting material. The residue was filtered through silica gel and purified by column chromatography to provide 7-oxo-isoambrox (7) as a white solid: m.p. $64-67^{\circ} \mathrm{C}$ (hexane-CHCl$) ;[\alpha]_{\mathrm{D}}{ }^{20}=+9.5^{\circ}\left(\mathrm{c}=0.48 ; \mathrm{CHCl}_{3}\right)$. IR $v_{\max } \mathrm{cm}^{-1} 2960$ - $2840(\mathrm{C}-\mathrm{H}), 1715(\mathrm{C}=\mathrm{O}), 1350(\mathrm{C}-\mathrm{H}), 1085(\mathrm{C}-\mathrm{O}) .{ }^{1} \mathrm{H}-\mathrm{NMR}(200 \mathrm{MHz}): \delta$ $3.85-3.40(\mathrm{~m}, 2 \mathrm{H}, \mathrm{H}-12) ; 2.52-2.32$ (m, $2 \mathrm{H}, \mathrm{H}-6) ; 1.37$ (s, 3H, 10-Me) 0.94, $0.90,0.72$ (2 x s, 9H, 4-Me- $\beta, 4-\mathrm{Me}-\alpha, 8$-Me- $\alpha$ ). ${ }^{13} \mathrm{C}-\mathrm{RMN}(50 \mathrm{MHz}): \delta 213.2$ (C-7); 85.8 (C-8); 66.6 (C-12); 61.8 (C-5); 49.1 (C-9); 41.6 (C-3); 41.3 (C-1); 37.0 (C-10); 35.3 (C-6); 33.0 (C-4); 32.5 (C-19); 26.8 (C-11); 26.4 (C-20); 21.3 (C-18); 18.1 (C-2); 14.9 (C-17).

\section{7a-Hydroxy-ambrox (3)}

To $350 \mathrm{mg}(1.30 \mathrm{mmol})$ of $8 \beta$-methyl- $7 \alpha, 8 \alpha, 12$-drimantriol (13) in 10 $\mathrm{mL}$ of dry pyridine, $149 \mathrm{mg}(1.30 \mathrm{mmol})$ of mesylchloride were added. The mixture was stirred under nitrogen at $0{ }^{\circ} \mathrm{C}$ for $24 \mathrm{~h}$, then poured into water $(20 \mathrm{~mL})$ and extracted with EtOAc $(3 \times 30 \mathrm{~mL})$. The combined organic layers were washed with $\mathrm{HCl}(5 \%)$, saturated $\mathrm{NaHCO}$ solution, and water, dried $\left(\mathrm{Na}_{2} \mathrm{SO}_{4}\right)$ and concentrated in vacuo. The solid obtained was purified by column chromatography to yield $7 \alpha$-hydroxy-ambrox (3) $(310 \mathrm{mg}, 95 \%)$ as a white solid, m.p. $62-63{ }^{\circ} \mathrm{C}\left(\mathrm{CHCl}_{3}-\right.$ hexane $) ;[\alpha]_{\mathrm{D}}^{20}=-66.0^{\circ}\left(\mathrm{c}=0.89 ; \mathrm{CHCl}_{3}\right)$. IR $v_{\text {cm }} \mathrm{cm}^{-1} 3410(\mathrm{OH}), 2980-2830(\mathrm{C}-\mathrm{H}), 1380(\mathrm{C}-\mathrm{H}), 1065(\mathrm{C}-\mathrm{O}), 1010(\mathrm{C}-\mathrm{O})$. 'H-NMR (200 MHz): $\delta$ 3.98-3.77 (m, 3H, H-7 + H-12); 2.56 (bs 1H, OH); 1.09 (s, 3H, 10-Me); 0.88, 0.84 (2 x s, 9H, 4-Me- $\beta, 4-\mathrm{Me}-\alpha, 8-\mathrm{Me}-\beta) .{ }^{13} \mathrm{C}-\mathrm{RMN}(50$ MHz): $\delta 81.4$ (C-8); 71.2 (C-7); 65.4 (C-12); 51.8 (C-9); 48.7 (C-5); 42.3 (C-3); 39.6 (C-1); 36.0 (C-10); 33.2 (4-Me- $\beta$ ); 32.5 (C-4); 26.1 (C-6); 22.1 (C-11); 21.2 (10-Me); 21.1 (4-Me- $\alpha$ ); 18.3 (C-2); 14.6 (8-Me- $\beta$ ). MS $m / z$ (rel. int.): $252\left[\mathrm{M}^{+}\right.$, $\left.\mathrm{C}_{16} \mathrm{H}_{28} \mathrm{O}_{2}\right](52) ; 237$ (10); 219 (2); 137 (100); 124 (8); 109 (25); 107 (4); 99 (2); 96 (1); 95 (4); 84 (8); 83 (8); 82 (6); 81 (12); 44 (81); 41 (31).

\section{7-Ox0-ambrox (4)}

To a stirred solution of $7 \alpha$-hydroxy-ambrox (3), $260 \mathrm{mg}(1.03 \mathrm{mmol})$ in $15 \mathrm{~mL}$ of $\mathrm{CH}_{2} \mathrm{Cl}_{2}$, PCC reagent $600 \mathrm{mg}(2.78 \mathrm{mmol})$ was added dropwise at room temperature. The reaction was monitored by TLC until disappearance of the starting material. The residue was filtered through silica gel and purified by column chromatography to yield 7-oxo-ambrox 4 as a white solid m.p. 133 $-134^{\circ} \mathrm{C}\left(\mathrm{CHCl}_{3}\right.$-hexane $) ;[\alpha]^{20}=-146.8^{\circ}\left(\mathrm{c}=0.98 ; \mathrm{CHCl}_{3}\right)$. IR $v_{\text {max }} \mathrm{cm}^{-1} 2980$ - $2870(\mathrm{C}-\mathrm{H}), 1720(\mathrm{C}=\mathrm{O}), 1380(\mathrm{C}-\mathrm{H}), 1010(\mathrm{C}-\mathrm{O}) .{ }^{1} \mathrm{H}-\mathrm{NMR}(200 \mathrm{MHz}): \delta$ $3.97-3.68$ (m, 2H, H-12); 2.69-2.25 (m, 2H, H-6); 1.28 (s, 3H, 10-Me); 1.02, 0.83 ( 2 x s, 9H, 4-Me- $\beta, 4-\mathrm{Me}-\alpha, 8-\mathrm{Me}-\beta) .{ }^{13} \mathrm{C}-\mathrm{RMN}(50 \mathrm{MHz}): \delta 208.8$ (C-7); 85.8 (C-8); 65.0 (C-12); 60.4 (C-9); 58.9 (C-5); 41.6 (C-3); 39.3 (C-1); 36.8 (C10); 35.8 (C-6); 33.5 (C-4); 32.8 (4-Me- $\beta$ ); 21.7 (C-11); 20.5 (4-Me- $\alpha$ ); 19.8 (10-Me); 17.9 (C-2); 14.4 (10-Me- $\beta$ ). MS $m / z$ (rel. int.): $250\left[\mathrm{M}^{+}, \mathrm{C}_{16} \mathrm{H}_{26} \mathrm{O}_{2}\right]$ (15); 222 (32); 138 (7); 137 (100); 124 (54); 127 (27); 109 (24); 108 (1); 107 (2); 96 (1); 95 (10); 84 (20); 83 (20); 82 (5); 81 (17); 41 (39).

\section{7ß-Hydroxy-ambrox (5)}

To a suspension of (t-BuO) $)_{3} \mathrm{AlH}(40 \mathrm{mg}, 0.11 \mathrm{mmol})$ in dry THF $(10 \mathrm{~mL})$, a solution of 7-oxo-ambrox (4) $(40 \mathrm{mg}, 0.16 \mathrm{mmol})$ solution in THF $(10 \mathrm{~mL})$ was added dropwise. The reaction mixture was refluxed for $2 \mathrm{~h}$, then EtOAc (10 $\mathrm{mL})$ and $1 \mathrm{~N} \mathrm{HCl}(10 \mathrm{~mL})$ were successively added to decompose the excess (t-ButO) $)_{3} \mathrm{AlH}$. After extraction with EtOAc $(3 \times 25 \mathrm{~mL})$ the combined organic extracts were washed with $\mathrm{NaHCO}_{3}$ solution, water, dried, and concentrated. The crude product was purified by column chromatography to yield 36.2 $\mathrm{mg}(22 \%)$ of $7 \alpha$-hydroxy-ambrox 3 (the less polar fraction). The more polar fraction yielded $7 \beta$-hydroxy-ambrox $(\mathbf{5}),(62 \mathrm{mg}, 61.5 \%)$ as a white solid: m.p. $149-150{ }^{\circ} \mathrm{C}$ (hexane-CHCl$) ;[\alpha]_{\mathrm{D}}^{20}=-34.6^{\circ}\left(\mathrm{c}=0.61 ; \mathrm{CHCl}_{3}\right)$. IR $v_{\max } \mathrm{cm}^{-1}$ $3420(\mathrm{OH}), 2980-2860(\mathrm{C}-\mathrm{H}), 1380(\mathrm{C}-\mathrm{H}), 1030(\mathrm{C}-\mathrm{O}) .{ }^{1} \mathrm{H}-\mathrm{NMR}(200 \mathrm{MHz})$ : ठ 3.98-3.50 (m, 3H, H-7 + H-12); 1.09 (s, 3H, 10-Me); 0.89, 0.84 (2 x s, 9H, $4-\mathrm{Me}-\beta, 4-\mathrm{Me}-\alpha, 8-\mathrm{Me}-\beta) .{ }^{13} \mathrm{C}-\mathrm{RMN}(50 \mathrm{MHz}): \delta 83.8$ (C-8); 78.5 (C-7); 65.2 (C-12); 58.4 (C-9); 55.9 (C-5); 42.1 (C-3); 39.6 (C-1); 35.7 (C-10); 33.5 (4-Me- $\beta$ ); 33.0 (C-4); 28.8 (C-6); 22.3 (C-11); 21.0 (4-Me- $\alpha$ ); 18.3 (C-2); 15.7 (10-Me); 15.0 (10-Me- $\beta$ ). MS $m / z$ (rel. int.): $252\left[\mathrm{M}^{+}, \mathrm{C}_{10} \mathrm{H}_{2}\right]$ (55); 237 (7); 137 (100); 124 (40); 123 (5); 109 (26); 107 (5); 96 (1); 95 (7); 84 (7); 83 (10); 82 (7); 81 (11); 44 (45); 81 (17); 41 (31). 


\section{RESULTS AND DISCUSSION}

Following our studies on the transformation of the main component of Drimys winteri to obtain compounds with ambergris-like odours, ${ }^{12-14}$ we now describe a formal synthesis of the oxygenated derivatives of Ambrox and Isoambrox, $\mathbf{3 , 4 , 5 , 6 , 7}$ and $\mathbf{8}$, which involves an alternative access to $\mathbf{9}$, the direct precursor of $\mathbf{3 , 4 , 5 , 6 , 7}$ and $\mathbf{8}$. The starting material was the sesquiterpene (-)-drimenol readily available from the bark of $D$. winteri.

Epoxidation of 8-methyl-12-acetoxy-7,8-drimene (9) with mCPBA in $\mathrm{CH}_{2} \mathrm{Cl}_{2}$ at $0^{\circ} \mathrm{C}$ gave the $\alpha$-epoxide 10 (69\% yield). The compound was characterized by ${ }^{1} \mathrm{H}$ NMR and ${ }^{13} \mathrm{C}$ NMR spectra. The $\alpha$-stereochemistry for the $\mathrm{C}-7$ proton is indicated by the $\mathrm{W}_{1 / 2}$ value $(7 \mathrm{~Hz})$ of the signal at $\delta 2.96$. These results led us to the conclusion that the reagent attacks from the less hindered $\alpha$-face of the double bond, and the stereochemistry of the epoxide was consequently assigned as $\alpha$. Surprisingly, treatment of $\mathbf{1 0}$ with $\mathrm{LiAlH}_{4}$ led us to the $7 \alpha$-hydroxy-isoambrox (6) in $23 \%$ yield and produced a mixture of epimeric diols. Compound $\mathbf{6}$ was characterized by ${ }^{1} \mathrm{H}$ NMR spectroscopy, which showed multiplet at $\delta 3.66-4.11$, which was assigned to $\mathrm{H}-7+\mathrm{H}-12$. The INEPT ${ }^{13} \mathrm{C}$ NMR spectrum showed the signal of $\mathrm{C}-12$ at $\delta 65.7\left(\mathrm{CH}_{2}\right)$, the signal of $\mathrm{C}-7$ at $\delta 70.4(\mathrm{CH})$, and the signal of $\mathrm{C}-8$ at $\delta 85.4(\mathrm{C})$, confirming that it was joined to the oxygen. The stereochemistry of 6 has been established by comparing the spectrum of ambrox and isoambrox using Beierbeck and Saunders parameters. ${ }^{15}$ All other signals were in agreement with those found for drimane models. ${ }^{12,13}$ Besides, chemical support for the structure of compound $\mathbf{6}$ was obtained by $(\mathrm{t}-\mathrm{BuO})_{3} \mathrm{AlH}$ reduction of $\mathbf{1 0}$. Spectroscopic data were in agreement with the values reported for $\mathrm{LiAlH}_{4}$ reduction.

Oxidation of 9 with $\mathrm{OsO}$ and co-oxidant $\mathrm{N}$-methylmorpholine $\mathrm{N}$-Oxide in acetone, $t$-butyl alcohol and water gave the mixture of acetyl diols in $98 \%$ yield. Attempts to separating this mixture did not give acceptable results and it was decided to try saponification. After separation, the triols $\mathbf{1 3}$ and $\mathbf{1 4}$ were identified by ${ }^{1} \mathrm{H}$ NMR. Triols $\mathbf{1 3}$ and $\mathbf{1 4}$ were used as the starting materials for the synthesis of derivatives of ambrox and isoambrox.

The cyclization of $\mathbf{1 3}$ and $\mathbf{1 4}$ to give $7 \alpha$-hydroxy-ambrox (3) and $7 \beta$ hydroxy-isoambrox (8) was carried out in $95 \%$ and $36 \%$ yields, respectively, using mesyl chloride in pyridine. The stereochemistry of the C-7 hydroxyl group in compound $\mathbf{8}$ is confirmed by the $\mathrm{W}_{1,2}$ value $(24 \mathrm{~Hz})$ of the signal at $\delta$ 3.31. Oxidation of $7 \alpha$-hydroxy-ambrox (3) and $7 \beta$-hydroxy-isoambrox (8) with PCC reagent in $\mathrm{CH}_{2} \mathrm{Cl}_{2}$ gave the corresponding ketones $\mathbf{4}$ and 7 in $99 \%$ and $95 \%$ yields. These ketones were characterized by ${ }^{13} \mathrm{C}$ NMR spectrum showed the chemical shifts of C-7 at $\delta 208.7$ and 213.2 respectively, clearly deshielded when compared with $\mathrm{C}-7$ of $\mathbf{3}$ and $\mathbf{8}$. Chemical support for the stereochemistry of compound 3 was obtained by Huang-Milong reduction of $\mathbf{4}$, which gave ambrox in $90 \%$ yield. Its spectroscopic data were in agreement with the values reported by Cortés. ${ }^{13}$

Finally, reduction of 7-oxo-ambrox (4) and 7-oxo-isoambrox (7) with (t$\mathrm{BuO})_{3} \mathrm{AlH}$ gave $7 \beta$-hydroxy-ambrox (5) and $7 \alpha$-hydroxy-isoambrox (6) in $50 \%$ and $61 \%$ yield, respectively.

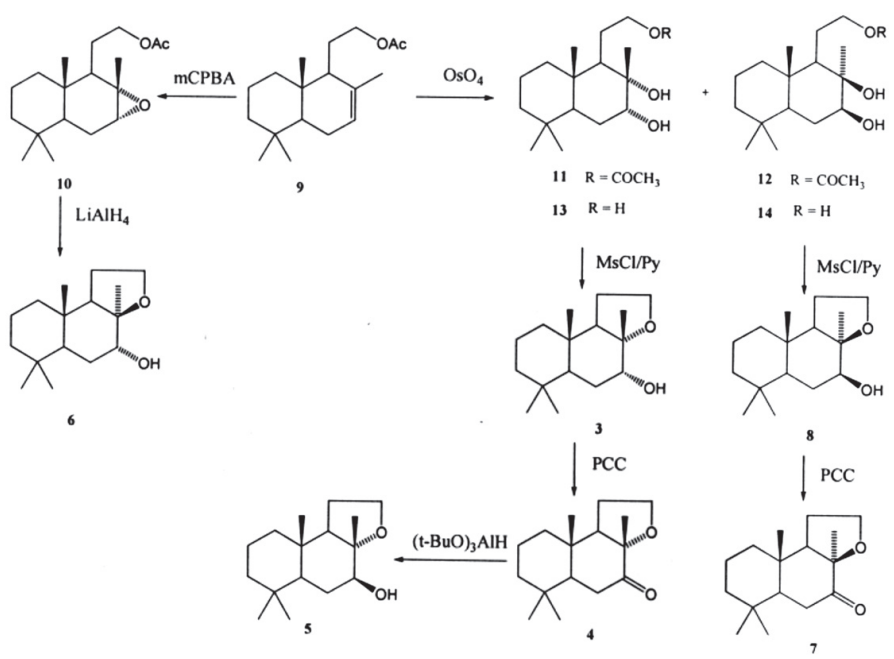

Scheme 1. Chemical synthesis of oxygenated derivatives of Ambrox and Isoambrox.

\section{CONCLUSION}

In conclusion this work is an important contribution to a simple and inexpensive methodology for the preparation of new oxygenated derivatives in position 7 of ambrox and isoambrox from a readily available starting material. From a qualitative point of view these results are promising, and the new oxygenated derivatives will be submitted to evaluation by qualified perfumers because they may provide significantly to structure-odoriferous properties relations.

\section{ACKNOWLEDGMENTS}

We acknowledge with thanks the financial support of the Dirección de Investigación, Universidad Arturo Prat, and of the Pontificia Universidad Católica de Chile.

\section{REFERENCES}

1.- Ohloff, G. The fragrance of Ambergris. In: Fragrance Chemistry. The science of the sense and smell. E.T. Theimer (ed.) Academic Press, New York, 1982, pp 535-573

2.- Sell, C. Chemistry and Industry. 1990, 20, 516-520.

3.- Escher, S.; Giersch, W.; Niclass, Y.; Bernardinelli, G. and Ohloff, G. Helvetica Chimica Acta 1990, 73, 1935-1947.

4.- Frater, G. and Lamparsky, D. In: perfumes, art, science and technology. P. M. Muller and D. Lamparsky (eds). Elsevier Applied Science, New York. 1991. p 289, and references cited therein.

5.- Barton, D.H.R., Taylor, D.K. and Tse, C. Tetrahedron, 1994, 35 , 9505-9508.

6.- Koyama H, Kaku Y and Ohno M. Tetrahedron Letter, 1987, 28, 2863-2867.

7.- Decorzant R, Vial C, Näf F and Whitesides G. M. Tetrahedron, 1987, 43, 1871-1879.

8.- Coste-Maniere, I.C, Zahra J. P and Waegell B. Tetrahedron Letter, 1988, 29, 1017-1018.

9.- Christensen P.A. Tetrahedron, 1988, 44, 1925-1932.

10.- Mori K and Tamura H. Liebigs Annalen der Chemie 1990, 361366.

11.- González-Sierra M, Rúveda EA, López JT and Cortés M. Heterocycles, 1987, 26, 2801-2804.

12.- Maturana H, Sierra J, López J and Cortés M. Synthetic Communications, 1984,14, 661-674.

13.- Cortés M, Armstrong M, Reyes E, López J and Madariaga E. Synthetic Communications, 1996, 26, 1995-2002.

14.- Apple H, Brooks C and Overton K. Journal Chemical Society, 1959, 3322-3323.

15.- Colombo M, Bustos D, Gonzalez-Sierra M, Olivieri A, and Ruveda E. Canadian Journal of Chemistry, 1986, 64, 552-555. and references cited therein. 